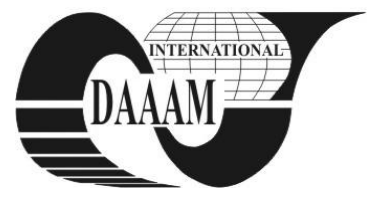

\title{
RESEARCH OF THE HEIGHT PARAMETERS OF THE MACHINED SURFACE
}

\section{SALIHU, A[vdi] H[ajdin]; ZEQIRI, H[akif] M[ehmet]; BUNJAKU, A[vdyl]; QEHAJA, N[exhat] E.; OSMANI, H[ysni] \& ZEQIRI, F[itim]}

\begin{abstract}
In this work are presented results for research roughness of height parameters of the machined surface during turning. The turning is performed on the machined steel C45, applying the methods of planning of poly factorial experiments, using as cutting tool the ceramic insertsMC2 of the Hertell company. The measurements are carried out by means of profile graph meter model Talasurf 6 of the company Taylor Hobson.

Key words: roughnes, skews, feed, cutting speed
\end{abstract}

\section{INTRODUCTION}

Surface integrity is a term that involves several considerations: surface finish and freedom cracks, chemical change, thermal damage (burn, transformation, and over tempering), and adverse residual stress. The first of these (surface finish) is by far the most important for finishing operations. The others are mainly a concern relative to ground surfaces (Milton, 2005).

In engineering design and production, it is important to be able to specify the degree of surfaces roughness desired. Before 1939 this was done by use of tactual standards. This involved the use of a series of specimens that had different finishes. The man in the shop used these specimens by running his fingernail first across a standard tactual surface and then across the surface he was producing. The topography of a surface can be divided into three different categories: form, waviness and roughness depending on the wavelength or peakto-peak spacing of the surface features (Bodinaku, 2006).

For evaluating the quality of a surface, the most useful are the moment of second, third and fourth order, symbolized by $\mathrm{Rq}$, Rsk, Rku, respectively. The shape of the asperities is adequate represented by Rsk and Rku

Skewness (Rsk): represents the degree of bias, or asymmetry of the profile about the mean line. A positive skew represents peaks, whereas a negative skew indicates valleys shown on 1.

$$
R_{s k}=\frac{1}{R_{q}^{3}} \frac{1}{L} \int_{0}^{L} Z^{3}(x) d x
$$

Kurtosis (Rku): the measure of the peak-ed-ness of the profile about the mean line. Kurtosis is an indication of how quickly a roughness feature rises over a given length. High kurtosis values represent quickly rising features, while low kurtosis values indicate gradual rising roughness features shown on 2.

$$
R_{k u}=\frac{1}{R_{q}^{4}} \frac{1}{N} \int_{0}^{L} Z^{4}(x) d x
$$

In this paper is presented experimental research for skewness and kurtosis.

\section{CONDITIONS DURING EXPERIMENTATION}

Machine: The experiments for measurement of roughness parameters of the surface processed are realize by numeric lathe model MD 55 GILDEMEISTER $\mathrm{P}=(1.85-25) \mathrm{kW}$ with rotating fields $\mathrm{nr} . \mathrm{n}=(100-4000) \mathrm{rev} / \mathrm{min}$ and feed $(0.001-39.99) \mathrm{mm} / \mathrm{rev}$.

Metal cutting tool: There are used cutting inserts: SNGN 120708 -120712-120720 from mixed ceramic $\left(\mathrm{Al}_{2} \mathrm{O}_{3}+\mathrm{TiC}\right)$ of HERTELL company. It is used the holder CSRNR $25 \times 25$ $\mathrm{M} 12 \mathrm{H} 3$ that the cutting edge takes these values: $\chi=75^{\circ}, \chi_{1}=15$ ${ }^{\circ}, \quad \gamma=-6^{o}, \quad \alpha=6^{o}, \lambda=-6^{\circ}, r_{\varepsilon}=0.8-1.2-2.0 . m_{\gamma_{f}}=-20^{\circ} \quad$, $b_{f}=0.2 . \mathrm{mm}$

Mesaure device: Measurement of parameters of the roughness on the processed surface is done with the computer measurement equipment Talasurf 6 of Taylor Hobson company. (Salihu, et al. 2001).

Reseach material: The rings are made of $\mathrm{C} 45$ material (acording to DIN) in normal situation with strength in limits of 185-200 HB with dimensions $\emptyset 170$ x 80 x 25 mm

Processing parameters: The research process is realized with the change of v, $s, a$ and $r$ presented in table 1 using the plan with many factors of the first row $\left(2^{4}+4\right)$ (Stankov, 1982).

\begin{tabular}{|c|cc|c|c|c|c|}
\hline \multicolumn{5}{|c|}{ CHARACTERISTICS OF INDIPENDENT DIFFERENT SIZES } \\
\hline $\mathrm{Nr}$ & & Note & $\begin{array}{c}\text { Level } \\
\text { Code }\end{array}$ & $\begin{array}{c}\text { Maximal } \\
1\end{array}$ & $\begin{array}{c}\text { Average } \\
0\end{array}$ & $\begin{array}{c}\text { Minimal } \\
-1\end{array}$ \\
\hline 1 & $\mathrm{~V}$ & $(\mathrm{~m} / \mathrm{min})$ & $\mathrm{X} 1$ & 700,000 & 458,258 & 300,000 \\
2 & $\mathrm{~S}$ & $(\mathrm{~mm} / \mathrm{rrot})$ & $\mathrm{X} 2$ & 0.400 & 0,283 & 0,200 \\
3 & $\mathrm{a}$ & $(\mathrm{mm})$ & $\mathrm{X} 3$ & 1,600 & 0,894 & 0,500 \\
4 & $\mathrm{r}$ & $(\mathrm{mm})$ & $\mathrm{X} 4$ & 2,000 & 1,265 & 0,800 \\
\hline
\end{tabular}

Tab. 1. Conditions for experiment realization

\section{ANALYZE OF THE RESEARCH RESULTS}

Chosen plan and researched results are shown in table 2 . After processing of researched data are gained mathematical models 3 and 4 (Salihu, 2001). Graphic interpretation is shown in fig.1and fig 2. Surface with a positive skewness, such as turned surface have fairly high spikes that protrude above a flatter average. Surfaces with negative skewness, such as porous surface have fairly deep valleys in a smother plateau.

More random surfaces have a skew near zero. the skewness parameter correlates with load carrying capability, porosity, and other characteristics of surfaces produced by processes other than conventional machining.

A value of Rsk greater than about 1.5 magnitude (positive or negative) indicates that the surface does not have a simple shape and a simple parameter such as $\mathrm{Ra}$ is probably not adequate to characterize the quality of the surface.

Surfaces with a large positive skewness can cause large measurement errors when measured with skidded instruments, 
particularly if there is a large spacing between the spikes of surface.

$$
\begin{aligned}
& R_{s k}=6.017 \cdot v^{-0.173} \cdot s^{0.226} \cdot a^{-0.0208} \cdot r^{-0.2832} \\
& R_{k u}=2.180 \cdot v^{-0.0307} \cdot s^{-0.223} \cdot a^{-0.0404} \cdot r^{0.0436}
\end{aligned}
$$

\begin{tabular}{|c|c|c|c|c|c|c|}
\hline & \multicolumn{4}{|c|}{ REAL PLAN OF MATRICA } & \multicolumn{2}{|c|}{ RESULTS } \\
\hline $\begin{array}{l}\mathrm{Nr} \\
\text { ren }\end{array}$ & $\begin{array}{c}\mathrm{v} \\
(\mathrm{m} / \mathrm{min})\end{array}$ & $\begin{array}{c}\mathrm{s} \\
(\mathrm{mm} / \mathrm{rev})\end{array}$ & $\begin{array}{c}\mathrm{a} \\
(\mathrm{mm})\end{array}$ & $\begin{array}{c}\mathrm{r} \\
(\mathrm{mm})\end{array}$ & Rsk & Rku \\
\hline 1 & 300.000 & 0.200 & 0.500 & 0.800 & 1.830 & 2.560 \\
\hline 2 & 700.000 & 0.200 & 0.500 & 0.800 & 1.600 & 2.600 \\
\hline 3 & 300.000 & 0.400 & 0.500 & 0.800 & 1.630 & 2.130 \\
\hline 4 & 700.000 & 0.400 & 0.500 & 0.800 & 1.660 & 2.200 \\
\hline 5 & 300.000 & 0.200 & 1.600 & 0.800 & 1.700 & 2.530 \\
\hline 6 & 700.000 & 0.200 & 1.600 & 0.800 & 1.600 & 2.800 \\
\hline 7 & 300.000 & 0.400 & 1.600 & 0.800 & 1.700 & 2.330 \\
\hline 8 & 700.000 & 0.400 & 1.600 & 0.800 & 1.270 & 1.700 \\
\hline 9 & 300.000 & 0.200 & 0.500 & 2.000 & 1.170 & 2.500 \\
\hline 10 & 700.000 & 0.200 & 0.500 & 2.000 & 0.830 & 3.060 \\
\hline 11 & 300.000 & 0.400 & 0.500 & 2.000 & 1.570 & 2.230 \\
\hline 12 & 700.000 & 0.400 & 0.500 & 2.000 & 1.500 & 2.330 \\
\hline 13 & 300.000 & 0.200 & 1.600 & 2.000 & 1.170 & 2.330 \\
\hline 14 & 700.000 & 0.200 & 1.600 & 2.000 & 0.970 & 2.270 \\
\hline 15 & 300.000 & 0.400 & 1.600 & 2.000 & 1.600 & 2.730 \\
\hline 16 & 700.000 & 0.400 & 1.600 & 2.000 & 1.400 & 2.100 \\
\hline 17 & 458.258 & 0.283 & 0.894 & 1.265 & 1.600 & 2.800 \\
\hline 18 & 458,258 & 0.283 & 0.894 & 1.265 & 1.800 & 2.700 \\
\hline 19 & 458.258 & 0.283 & 0.894 & 1.265 & 1.800 & 2.800 \\
\hline 20 & 458.258 & 0.283 & 0.894 & 1.265 & 1.400 & 2.300 \\
\hline
\end{tabular}

Tab. 2. Derived results during experiment realization

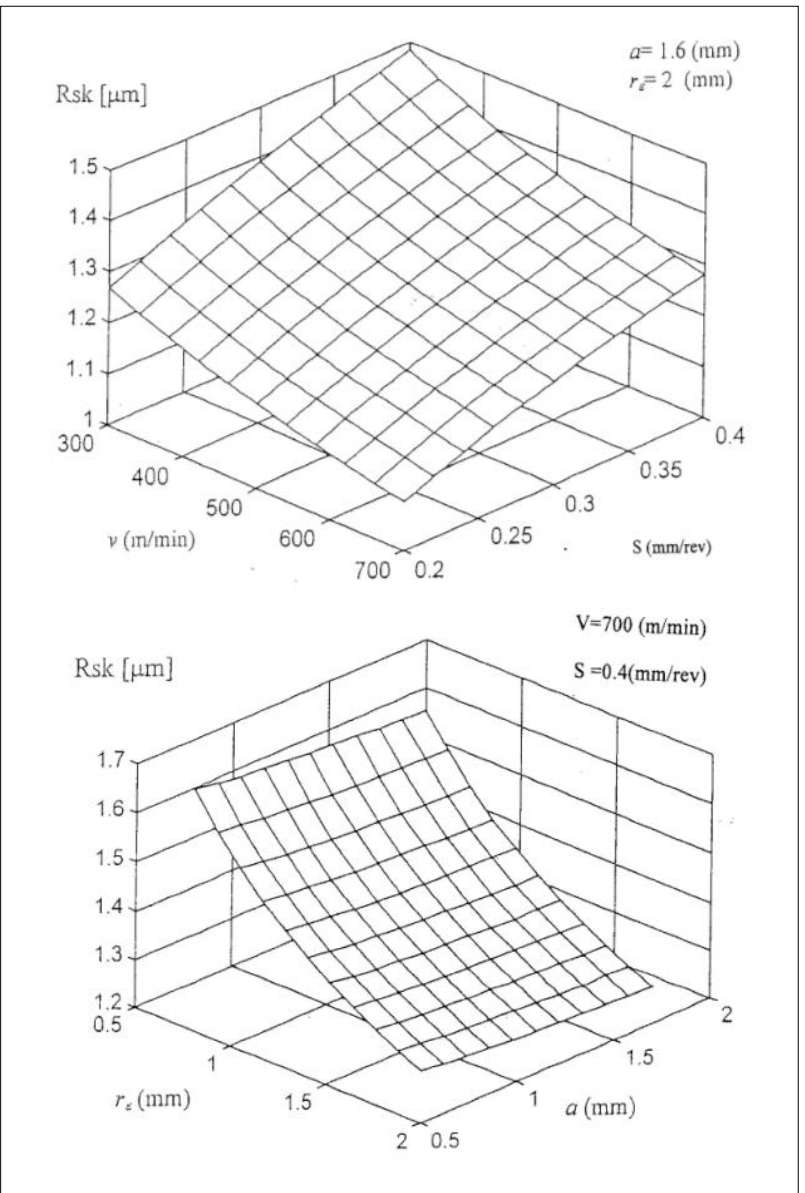

Fig. 1. Graphical interpretation of the mathematical models 3 .

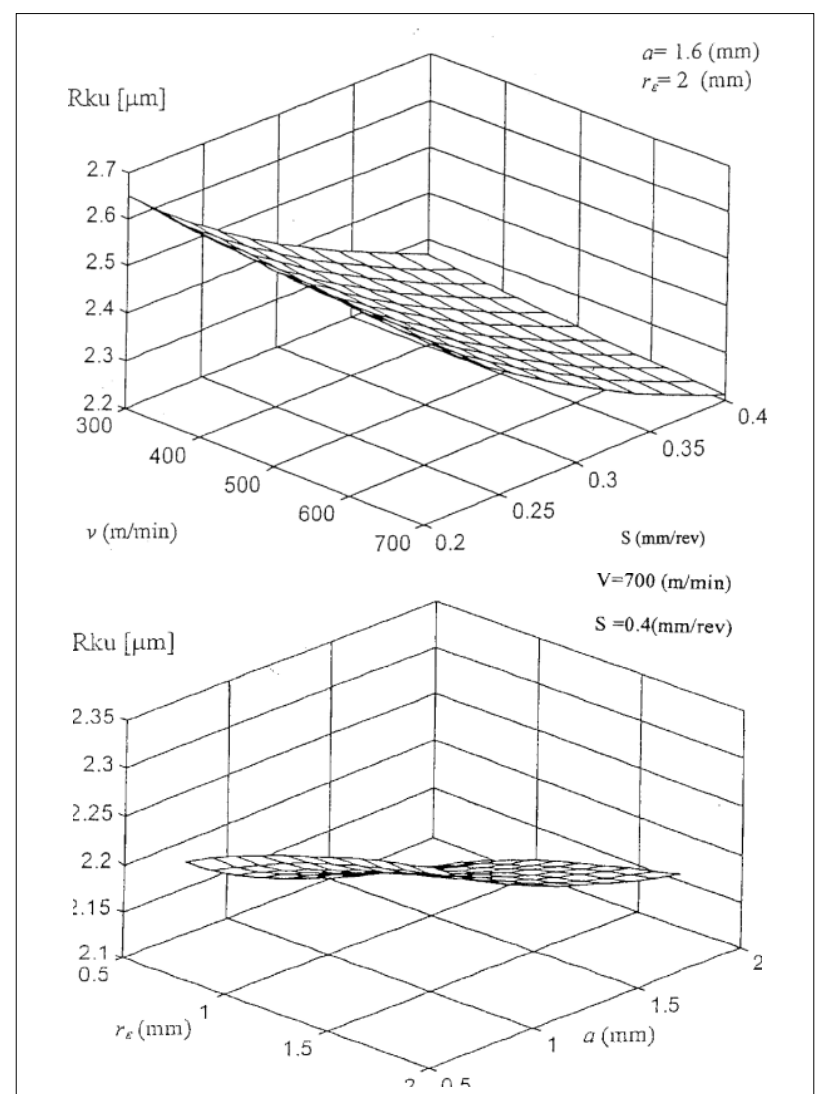

Fig. 2. Graphical interpretation of the mathematical models 4.

\section{CONCLUSION}

The analyses of obtained mathematical models make us possible to conclude that:

- the change of the parameters in the function of cutting parameters can be represented in step gradual function,

- the feed $s$ and cutting speed $v$ have an influence in increase of Rsk parameters, whereas cutting depth $a$ and nose radius $r$ have an influence in reduce.

- the nose radius $r$ and cutting speed $v$ have an influence in increase of Rku parameters, whereas cutting depth $a$ and fed $s$ have an influence in reduce. (Salihu, et al. 2001).

- Rsk illustrates load carrying capacity, porosity, and characteristics of nonconventional machining processes.

Results of the research are of the interest to show to exploited characteristics in the surface Lay by the choosing parameters.

\section{REFERENCES}

Bodinaku, A. (2006). Mechanical technology, Volume 2, Faculty of Mechanical Engineering, Tirana, Albania

Milton C. Shaw (2005). Metal cutting principles, Arizona state University, ISBN 0-19-514206-3, Oxford, New York.

Salihu, A. (2001). Research of mach inability of cutting material with increased speed, doctoral dissertation, Faculty of Mechanical Engineering, Prishtina

Salihu, A.; Zeqiri, H.; Bunjaku, A.; Qehaja, N.;Osmani, H \& Kycyku, A.(2009). Research of the horizontal parameters of the roughness machined surface by turning, Annals of DAAAM for 2009 and Proceedings of the $20^{\text {th }}$ international DAAAM symposium, "Intelligent Manufacturing\& Automation, Focus On Theory Practice and Education" Volume 20, ISBN 978-3-901509-70, ISSN 1726-9679, pp 0119-0120, Editor; B. Katalinic, 25-28, November Vienna

Stankov, J. (1982). Measurement technical basic, methods and experiments planning, FTN, Novi Sad 